Lepr Rev (1993) 64, 259-266

\title{
Evolution of early lesions in leprosy
}

\author{
BRAJENDRA MISHRA, ${ }^{*}$ A. MUKHERJEE, $\dagger$ \\ A. GIRDHAR, $\ddagger$ S. HUSAIN,$\ddagger$ G. N. MALAVIYA,$\ddagger \S$ \\ \& B. K. GIRDHAR $\ddagger$ \\ *Bhopal Gas Disaster Research Center (ICMR), Gandhi Medical \\ College Campus, Bhopal-462 001, India; †Institute of Pathology \\ (ICMR), Safdurjung, New Delhi, India; and $\ddagger$ Central JALMA \\ Institute for Leprosy (ICMR), PO Box 31, Tajganj, Agra-282 001, \\ India
}

\section{Accepted for publication 19 February 1993}

Summary We observed 29 patients presenting with vague peripheral neurological symptoms for 6 months or more. During this period, 16 developed clinical leprosy, 3 developed borderline tuberculoid leprosy and the other 13 developed neuritic leprosy. Of these 13 cases 11 subsequently developed skin lesions similar to those seen in indeterminate and in borderline tuberculoid leprosy. Based on the above observations, an attempt has been made to explain the evolution of early lesions of leprosy.

\section{Introduction}

Clinical leprosy is diagnosed by the presence of 2 of the 3 cardinal signs-hypopigmentation and/or infiltration of the skin, nerve thickening and/or anaesthesia and the presence of Mycobacterium leprae in skin or nerves. By the time 2 cardinal signs appear the leprosy lesions are well established. Can leprosy be diagnosed earlier than this?

It has been postulated that a hypopigmented patch, with or without anaesthesia, may not be the first clinical event in the course of the disease. There may be some preceding neurological symptoms which go unnoticed because of their insidious onset and vague appearance.

At present most diagnoses of leprosy, especially those made in the field, are based on clinical observations, and laboratory tests are used to provide additional supportive evidence in order to confirm the clinical diagnoses.

Taking into consideration the above, we undertook the present work, and selective patients attending the outpatient department at CJIL Agra were observed for about $2 \frac{1}{2}$ years.

§PO Box 25, GPO Agra, 282001 India. 


\section{Material and methods}

For this study we selected 29 people who voluntarily presented with certain neurological symptoms which they believed could probably be due to leprosy. These patients visited us more or less regularly over a long period, and could therefore be followed-up and included in the study, because it is difficult to study patients properly who present for some vague symptoms but stop coming after 1 or 2 visits. As a result a common denominator for the cases used in our study could not be established. Their neurological symptoms were localized to a particular site of the body and there was no clinical evidence of leprosy.

They were thoroughly examined in order to rule out leprosy or any other disease likely to be responsible for their symptoms. The 29 patients we selected for our study had an area of numbness or tingling, a sense of burning or heaviness or formication and incomplete or complete anaesthesia. They did not have any local or regional nerve thickening, hypopigmented or erythematous, raised or flat skin lesions.

Patients who had one or more of the above symptoms, along with associated nerve thickening, were diagnosed as cases of neuritic leprosy. When this was diagnosed the subjects were examined in good daylight to rule out any cutaneous lesion of leprosy.

The cases developing cutaneous manifestations were those who had one or more of the above symptoms along with ill- or well-defined, flat or raised, hypopigmented or infiltrated, single or multiple skin lesions.

Smear examinations were done from both ears and at least one from the site of the above-mentioned symptoms. Lepromin (Dharmendra) $0.1 \mathrm{ml}$, intradermal was given and the reaction was read after 24-48 hours. Erythema over $10 \mathrm{~mm}$ in diameter was considered as a positive reaction to lepromin. Biopsies were taken for histology in some cases. It was very difficult to convince our patients to undergo biopsy at the stage 'Under observation' because they were new to hospital and apparently there was nothing in the skin, therefore the majority of the biopsies could only be performed in later parts of the study.

All 29 cases kept under observation were given a placebo to ensure their regular visit. The moment the diagnosis of leprosy was made on clinical grounds, patients were put under appropriate antileprosy therapy consisting of dapsone $100 \mathrm{mgs}$ daily and Rifampicin 600 mgs once a month.

\section{VISIT SCHEDULE}

Patients usually visited at monthly intervals, but some of the cases reported a week earlier or later.

\section{OBSER VATIONS}

\section{Symptomatology}

All 29 cases had neurological symptoms which included impaired/altered sensation (in 24) and paraesthetic symptoms (in 7). Some of the cases had more than a single symptom. Slit skin smear examinations were done in 25 cases and all were negative for M. leprae. Lepromin status was examined in 17 cases and of these only 4 cases had a positive Mitsuda reaction and the remaining 13 were negative. 


\section{Histology}

We performed 16 biopsies on 11 patients at various stages of the disease. Of the 16 biopsies, 2 were performed on the areas of sensory impairment at the stage of 'under observation'. At the stage of 'Neuritic leprosy' 5 biopsies were performed and, finally, at the stage of 'Leprosy with cutaneous lesions' 9 biopsies were performed. Biopsies could be grouped as follows (see Table 1).

\section{Group I}

We performed 2 biopsies at the stage of 'Under observation', both obtained from the area of sensory impairment in cases 9 and 12. In case 9 there was no evidence of leprosy; however, on follow-up this case developed mononeuritic leprosy, followed by the appearance of an indeterminate lesion (proven histologically). In case 12, the skin showed BT histology at the stage of 'Under observation' (without any visible skin lesion) and on follow-up this case also developed mononeuritic leprosy and afterwards progressed to histologically proven clinical TT skin lesion (Table 1).

\section{Group II}

We performed 5 biopsies at the stage of 'Neuritic leprosy'. Two biopsies were performed on the anaesthetic skin, in case 1 there was no evidence of leprosy and in case 2 nonspecific changes were seen. 3 nerve biopsies on cases 1, 7 and 8 revealed BT/I, I/BT and BT histology, respectively, and 2 of these mononeuritic cases, 7 and 8, later developed histologically proven BT skin lesions. Case 1, another suffering from neuritic leprosy, demonstrated BT histology in nerves but no evidence of leprosy in skin biopsy (Table 1).

\section{Group III}

We performed 9 biopsies at the stage of 'Cutaneous leprosy' obtained from the cutaneous lesions and in all, except case 11, (cases 3, 4, 6, 7, 8, 9, 10 and 12), there was total concordance for disease. However, in case 11 non-specific changes were seen in clinical BT skin lesion (Table 1).

\section{EVOLUTION OF EARLY LEPROSY LESIONS}

The 29 cases we followed up to study altered sensation for between 6 months and $2 \frac{1}{2}$ years showed the following pattern (Figures 1 and 2):

(a) There was no change in 13 patients, and 1 had been suffering from anaesthesia in both upper limbs.

(b) Cases 1 and 2 while under observation progressed to the stage of mononeuritic leprosy.

(c) Cases 3, 4 and 5 while under observation developed borderline tuberculoid lesions in skin, without passing through the stage of 'Neuritic leprosy'; case 4 in this group at the stage of 'Under observation' showed symptoms similar to those seen in trigeminal neuralgia in an area inervated by the infraorbital branch of the trigeminal nerve. Later this patient developed a BT lesion exactly at the site of the initial symptom. In cases 3 and 5 lesions appeared at sites where it was difficult to palpate the cutaneous nerve. 
Table 1. Evolution of early lesions in leprosy

\begin{tabular}{|c|c|c|c|c|c|c|c|c|c|c|c|c|c|c|c|c|c|}
\hline \multirow[b]{3}{*}{ S. No. } & \multirow[b]{3}{*}{ Name } & \multirow[b]{3}{*}{ Age } & \multirow[b]{3}{*}{ Sex } & \multirow{3}{*}{$\begin{array}{l}\text { Duration of } \\
\text { altered } \\
\text { sansation } \\
\text { on first } \\
\text { visit } \\
\text { (months) }\end{array}$} & \multirow{3}{*}{$\begin{array}{c}\text { Smear } \\
\text { examination }\end{array}$} & \multirow[b]{3}{*}{ Lepromin } & \multirow{2}{*}{\multicolumn{2}{|c|}{$\begin{array}{c}\text { Under } \\
\text { observation } \\
\text { Histology }\end{array}$}} & \multirow{2}{*}{\multicolumn{2}{|c|}{$\begin{array}{l}\text { Period for } \\
\text { developing } \\
\text { neuritic } \\
\text { from stage } \\
\text { of U.O. }\end{array}$}} & \multicolumn{3}{|c|}{ Neuritic Leprosy } & \multirow{2}{*}{\multicolumn{2}{|c|}{$\begin{array}{l}\text { Transition } \\
\text { period for } \\
\text { change of } \\
\text { nuritic to } \\
\text { cutaneous } \\
\text { leprosy }\end{array}$}} & \multirow{2}{*}{\multicolumn{2}{|c|}{$\begin{array}{l}\text { Leprosy with } \\
\text { cutaneous } \\
\text { manifestation }\end{array}$}} \\
\hline & & & & & & & & & & & Clinical & Histo & $\log y$ & & & & \\
\hline & & & & & & & Nerve & Skin & Months & Days & Monopoly & Nerve & Skin & Months & Days & Clinical & Histology \\
\hline 1 & SL & 65 & M & - & $-\mathrm{Ve}$ & $-\mathrm{Ve}$ & - & - & 22 & 15 & M & $\mathrm{BT} / \mathrm{I}$ & NE & - & - & - & - \\
\hline 2 & MA & 35 & M & 14 & - & - & - & - & 9 & 07 & M & - & NSC & - & - & - & - \\
\hline 3 & MV & 35 & M & 12 & $-\mathrm{Ve}$ & $-\mathrm{Ve}$ & - & - & - & - & - & - & - & 5 & 10 & MBT & BT \\
\hline 4 & $\mathrm{SH}$ & 24 & M & $5 \cdot 5$ & $-\mathrm{Ve}$ & $+\mathrm{Ve}$ & - & - & - & - & - & - & - & 1 & 00 & BT & $\mathrm{T}$ \\
\hline 5 & PR & 35 & M & - & - & - & - & - & - & - & - & - & - & 0 & 28 & BT & - \\
\hline 6 & GD & 16 & $\mathrm{~F}$ & & $-\mathrm{Ve}$ & $-\mathrm{Ve}$ & - & - & 3 & 28 & M & - & - & 7 & 05 & BT & I \\
\hline 7 & MN & 18 & $\mathrm{M}$ & 36 & $-\mathrm{Ve}$ & $-\mathrm{Ve}$ & - & - & 3 & 15 & M & I/BT & - & 1 & 03 & BT & BT \\
\hline 8 & $\mathrm{RN}$ & 40 & $\mathrm{M}$ & - & $-\mathrm{Ve}$ & - & - & - & 0 & 28 & M & BT & - & 2 & 00 & BT & BT \\
\hline 9 & GR & 25 & $\mathbf{M}$ & - & $-\mathrm{Ve}$ & $+\mathrm{Ve}$ & - & $\mathrm{NE}$ & 6 & 00 & M & - & - & 0 & 19 & I & I \\
\hline 10 & $\mathrm{RS}$ & 50 & $\mathrm{M}$ & - & - & - & - & - & 0 & 23 & M & - & - & 1 & 07 & BT & I \\
\hline 11 & RNS & 40 & M & - & $-\mathrm{Ve}$ & $-\mathrm{Ve}$ & - & - & 5 & 25 & $\mathrm{P}$ & - & - & 0 & 20 & BT & NSC \\
\hline 12 & $\mathrm{RH}$ & 34 & $\mathrm{M}$ & 4 & $-\mathrm{Ve}$ & $-\mathrm{Ve}$ & - & $\mathrm{I} / \mathrm{BT}$ & 12 & 00 & M & - & - & 8 & 08 & BT & $\mathrm{I} / \mathrm{BT}$ \\
\hline 13 & SR & 25 & $\mathbf{M}$ & 36 & - & - & - & - & 4 & 20 & M & - & - & 0 & 23 & BT & - \\
\hline 14 & AS & 25 & $\mathbf{M}$ & 24 & $-\mathrm{Ve}$ & - & - & - & 11 & 00 & $\mathrm{M}$ & - & - & 17 & 17 & BT & - \\
\hline 15 & NN & 45 & $\mathbf{M}$ & - & $-\mathrm{Ve}$ & - & - & - & 23 & 00 & M & - & - & 4 & 11 & BT & - \\
\hline 16 & MU & 35 & M & - & $-\mathrm{Ve}$ & - & - & - & 0 & 23 & M & - & - & 1 & 03 & BT & - \\
\hline
\end{tabular}

NE: No evidence of leprosy, NSC: Nonspecific changes, MBT: Macular BT, NEUR: Neuritic Leprosy, UO: Under Observation, MONO: Mononeuritic, POLY: Polyneuritic, I: Indeterminate, BT: Borderline Tuberculoid. 


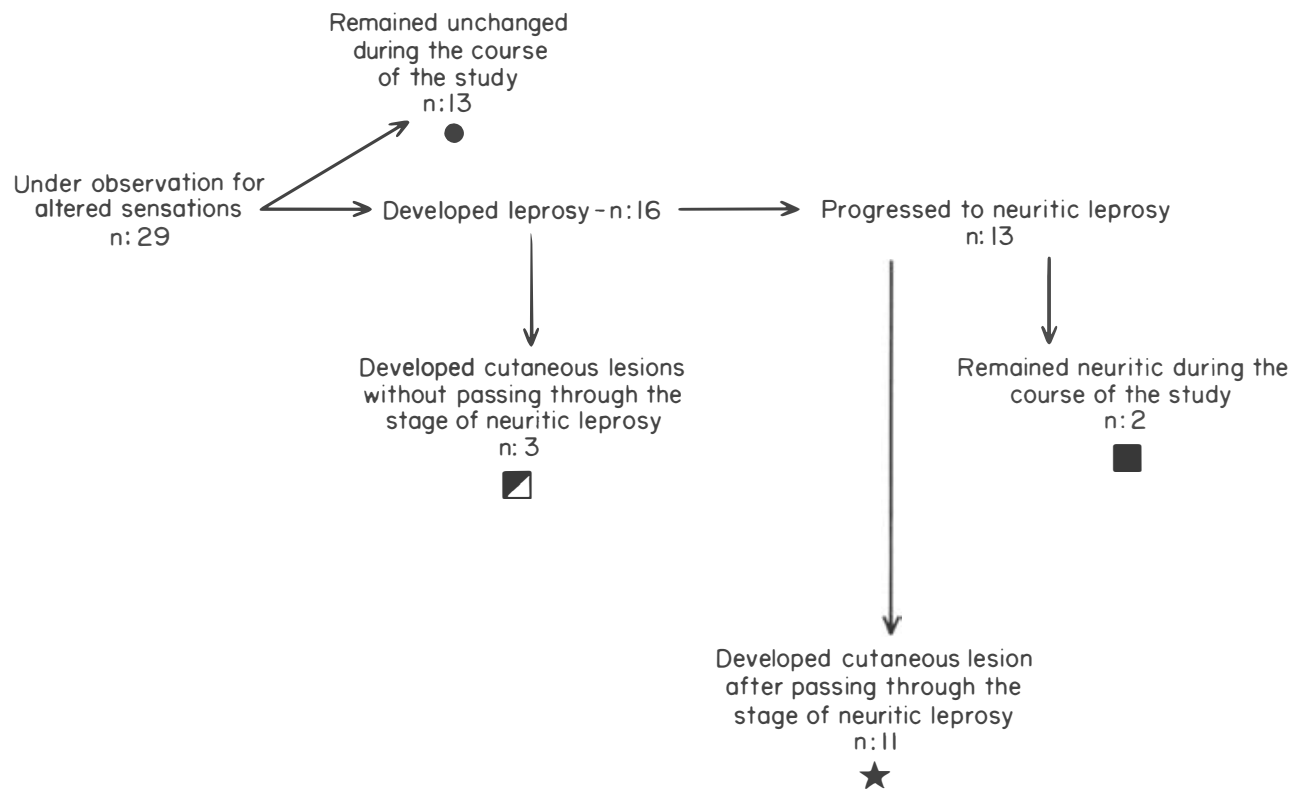

Figure 1. Course of events.

(d) In this category cases 6-16 'Under observation' passed through the stage of 'Neuritic leprosy' and later on developed BT lesions; 1 of these had multiple patches.

\section{TIME FRAME FOR THE EVOLUTION OF EARLY LEPROSY LESIONS}

The period the altered sensation had lasted in all the patients when they first visited the hospital varied from 2 to 30 months, averaging 18 months (A). The length of time taken to develop 'Neuritic leprosy' during the stage of 'Under observation' in hospital was also variable. The average period for 11 cases was about 5 months and 9 days (B), 2 cases (at serial numbers 1 and 15) being excluded because of their very high values. The average transition period from the stage of 'Neuritic leprosy' to 'Leprosy with cutaneous lesions' was calculated in a similar fashion and is 4 months and 2 days $(C)$. Thus it can be said that after noticing the altered sensation the average time taken to develop cutaneous leprosy is 27 months and 11 days (A (18 months) + B (5 months and 9 days $)+C$ (4 months and 2 days)).

The treatment was started once a definite clinical diagnosis of leprosy was made. This means that on average it took 4 months and 2 days for cutaneous lesions to appear following development of neuritic leprosy under treatment.

\section{Discussion}

The early diagnosis of leprosy has become a subject of great importance for the success of the leprosy eradication programme. Nowadays efforts are being made to diagnose leprosy 


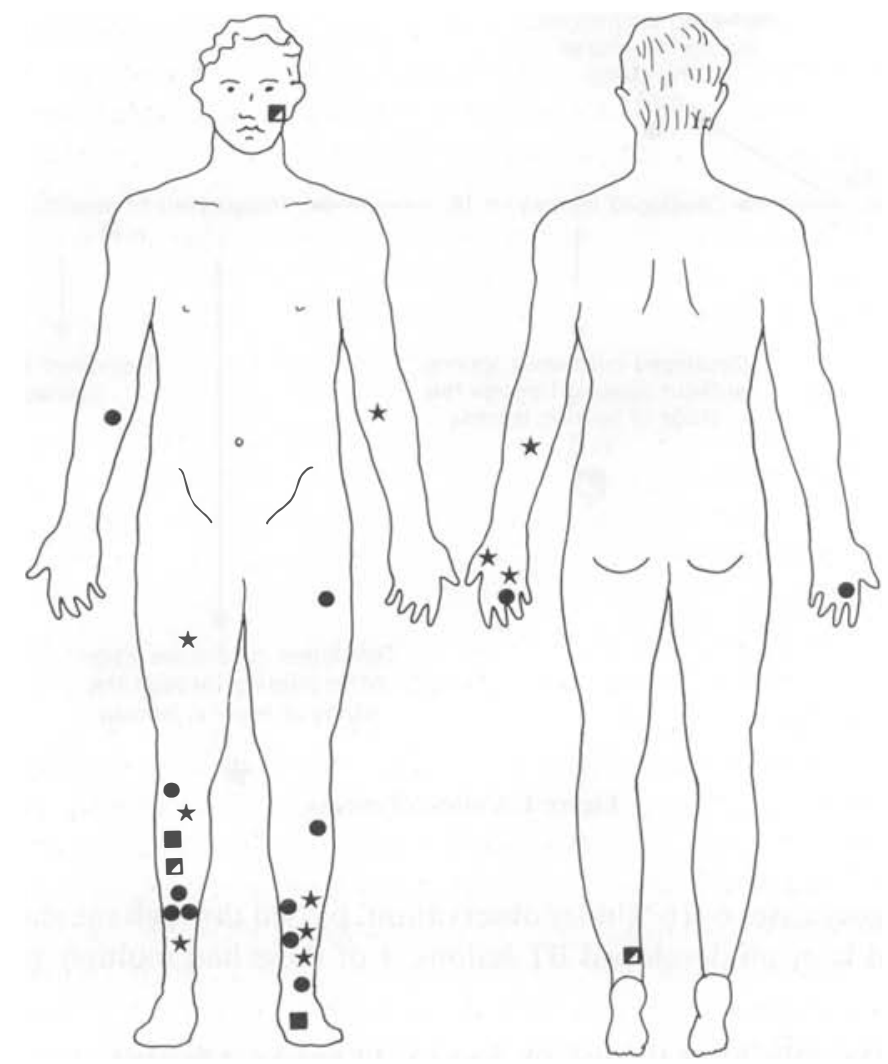

Figure 2. Site of the lesions. (Not depicted in figure:

1 case had anaesthesia on both upper limbs. 1 case developed multiple nerve trunk involvement and multiple cutaneous lesions.)

Legends:

- Remained unchanged during the course of the study. $\square$ Remained neuritic during the course of the study. $\star$ Developed cutaneous lesion after passing through the stage of neuritic leprosy. $\square$ Developed cutaneous lesions without passing through the stage of neuritic leprosy.

early with the help of immunological and biochemical tests, but these tests are not $100 \%$ accurate and doubts have been expressed about their efficacy. ${ }^{1}$ The interpretation of these tests is difficult in suspected cases where the results could be expected to be of greatest help. The tests are also available only at selected centres; therefore for field workers the early diagnosis of leprosy is likely to remain clinical. Efforts have been made in the present work to understand the significance of some of the neurological symptoms in the context of the early diagnosis of leprosy.

For all practical purposes, and as generally agreed, the earliest clinically manifest lesion of leprosy is a flat macule with slight hypopigmentation, ill-defined margins and questionable sensory impairment. This concept is well-accepted and propagated by others.

It is probably easier for both physician and patient to recall events in reference to an 
observed episode. A visible skin patch is such an episode in the natural history of leprosy and is likely to be the reason for the popularity of the above concept. In contrast, it is difficult to recall some vague neurological manifestation in reference to a long and variable time period and then correlate this with leprosy lesions appearing at a later date after a period varying from a few months to many years. This is even more likely when these neurological symptoms are insidious and observed infrequently for a varying period and are therefore easily forgotten or overlooked.

The importance of these neurological symptoms before the diseases manifest has been observed by Cochrane. ${ }^{2} \mathrm{He}$ writes: 'I am convinced that the first definite evidence of disease is seen in the appearance of an area of anaesthesia. This definite sign may be preceded by vague subjective symptoms such as tingling'. He further observed that between the onset of the first sign and the diagnosis of leprosy there was a gap of between 2 and 20 years. In the present study the interval between the onset of neurological symptoms and the definitive clinical diagnosis of cutaneous leprosy averaged about 27 months and 11 days.

In the present study no correlation of the symptomatic state or manifest disease could be established with factors like age, sex, immune status and bacteriological examination. Histologically, of the 11 cases biopsied, disease was confirmed in 9.

As happens in many other diseases all those who are infected do not necessarily develop the disease. Accordingly, in the present study of 29 cases only 16 developed the disease, with the remaining 13 remaining stationary. This period of observationconsidering the long incubation period of leprosy-was short, especially when it is accepted that a leprosy granuloma can remain incipient without clinical manifestations.

A similar transition to that observed in the present work, from 'Neuritic' to 'Leprosy with cutaneous manifestations' has been observed by Noordeen ${ }^{3}-1$ case; Chack ${ }^{4}-2$ cases; Shenoi \& Padhee ${ }^{5}-1$ case and by Talwar et al. ${ }^{6}-8$ cases, covering the total spectrum except BL/LL.

The transition period from the stage of 'Neuritic leprosy' to 'Leprosy with cutaneous lesions' has been observed in the present study, with an average of 4 months 2 days. Similar observations have been made by us in another series of 16 cases with an average transition period of 3 months 8 days (under communication). ${ }^{7} \mathrm{~A}$ transition time of 2-6 months has been observed by Talwar et al. ${ }^{6}$

The events which trigger such changes remain illusive and raise the following questions:

1 Is neuritic leprosy an early form of cutaneous leprosy which, under the influence of some factors as yet unknown, remains stationary for a varying period?

2 Is the appearance of a skin patch an outcome of immunological upgrading or downgrading?

3 What is the potential of neuritic leprosy with lepromatous histology, negative smear and lepromin negativity to progress to cutaneous lepromatous leprosy?

4 Probably the answer can be obtained if neural and cutaneous biopsies are available for comparison.

In this preliminary study, a definite sequence of vague neurological symptoms (prodromal stage?) and the subsequent development of manifest disease-i.e. first neuritic and later cutaneous, has been observed. Cochrane suggested this possibility and mentioned it in his book. ${ }^{2}$ 
Some questions need answering. As observed in the present study, is there a definite sequence of paraesthetic prodromal symptoms prior to the development of neuritic leprosy transforming further in at least a proportion of the cases to cutaneous forms in the field situation as well? And can leprosy be diagnosed on the strength of these symptoms? This subject requires some long-term studies at least in contacts of known leprosy cases with such symptoms. Some of these can be subjected to neural and cutaneous histology for understanding the natural history of the disease. In hyperendemic areas people with these neurological symptoms can be placed under surveillance for at least 5 years.

\title{
References
}

1 Dharmendra. Indeterminate group, Volume 1. Bombay: Kothari Medical Publishing House, 1978, pp. 44-7.

2 Cochrane, RG. Leprosy in Theory and Practice, Cochrane RG, Davey TF (eds). London: John Bristol and Company, 1964, p. 251 .

3 Noordeen SK. Epidemiology of (Poly)neuritic type of Leprosy. Lepr India, 1972; Vol. XLIV, No. 2: 90-6.

${ }^{4}$ Chacko GJG. Evolution of pathological lesions in leprosy patients and their immunological significance. Proceedings of Indo-U.K. symposium on leprosy, April 17-10, 1986; 82-89.

5 Shenoi SD, Padhee A. Polyneuritic leprosy changing in borderline line tuberculoid (BT). Ind J Le pr, 1990; 62: 363.

6 Talwar S, Jha PK, Tiwari VD. Neuritic leprosy epidemiology and therapeutic responsiveness. Lepr Rev, 1992; 63: 263-8.

7 Brajendra Mishra, Mukherjee Ashok, Girdher Anita, Husain Sajid, Malaviya GN, Girdher BK. Neuritic leprosy: further progression (under communication).

Lepr Rev (1993) 64, 259-266

\section{Evolution des lésions précoces dans la lépre}

\author{
Brajendra Mishra, A. Mukherjee, A. Girdhar, S. Husain, \\ G. N. Malaviya et B. K. Girdhar
}

Résumé Nous avons observé 29 malades qui présentaient de vagues symptômes neurologiques périphériques pendant 6 mois ou plus. Au cours de cette période, 16 ont manifesté une lèpre clinique: 3 une lèpre borderline tuberculoïde et les 13 autres une lèpre névritique; d'autre part, 11 ont manifesté par la suite des lésions cutanées similaires à celles observées dans les lèpres indéterminées et borderlines tuberculoïdes. Sur la base de ces observations, nous essayons d'expliquer l'évolution des lésions précoces de la lèpre.

\section{Evaluación de las lesiones tempranas en la lepra}

\author{
Brajendra Mishra, A. Mukherjee, A. Girdhar, S. Husain, \\ G. N. Malaviya y B. K. Girdhar
}

Resumen Hemos observado 29 pacientes con síntomas neurológicos periféricos inciertos por 6 meses o más. Durante este período, 16 desarrollaron lepra clínica, 3 lepra tuberculoide incierta, y los restantes 13 lepra neurítica, y 11 pacientes posteriormente desarrollaron lesiones dérmicas similares a las que se observan en la lepra tuberculoide incierta. Basándose en estas observaciones, se ha tratado de explicar la evolución de las lesiones tempranas en la lepra. 